\title{
THE DYNAMICS OF COLONIZING ARTHROPOD COMMUNITIES AT THE INTERFACE OF ABANDONED, ORGANIC AND COMMERCIAL APPLE ORCHARDS AND ADJACENT WOODLAND HABITATS
}

\author{
MIGUEL A. ALTIERI and LINDA L. SCHMIDT \\ Division of Biological Control, University of California, Berkeley, CA 94720 (U.S.A.)
}

(Accepted for publication 11 December 1985)

\section{ABSTRACT}

Altieri, M.A. and Schmidt, L.L., 1986. The dynamics of colonizing arthropod communities at the interface of abandoned, organic and commercial apple orchards and adjacent woodland habitats. Agric. Ecosystems Environ., 16: 29-43.

Considerable numbers of arthropods were intercepted by Malaise traps at the interface of abandoned, organic and sprayed apple orchards with adjacent woodlands. Low exchange of arthropods was registered between the abandoned orchard and its margins. The data suggest that arthropods invaded the orchards from the surrounding woodlands and subsequent colonization of trees was influenced by orchard management intensity, vegetational diversity and distance of trees from borders. More natural enemies established and remained in the organic orchards than in the sprayed orchard, whereas more rosy apple aphids and several species of leafhoppers invaded the sprayed orchard. A declining gradient in predator abundance on the apple trees was observed from abandoned to sprayed orchards, paralleling a decrease in vegetational diversity and an increase in management intensity. Predators were more abundant on trees close to the woodlands than in the centers of the managed orchards. Herbivores exhibited an opposite trend. The rates at which predators removed prey that were placed on cards in the trees and on the ground were higher in the field margins than in the centers of the organic and sprayed orchards. Predation was highest in the abandoned orchard and in the organic orchard with cover crop.

\section{INTRODUCTION}

Uncultivated habitats adjacent to agricultural areas can act as potential sources of colonization for pestiferous and beneficial arthropods. Many insect pests, such as aphids and leafhoppers, invade crop fields and orchards from edge vegetation, especially when the wild plants are botanically related to the crop (Dambach, 1948). For example, the presence of Urtica dioica L. in the herb layer of field boundaries of carrot fields is an important factor determining high levels of carrot fly (Psila rosae F.) larval damage to adjacent carrots (Wainhouse and Coaker, 1981). Similarly, adult leafhoppers, (Scaphytopius acutus Say), vectors of peach $\mathrm{x}$-disease, invade 
peach orchards from edge vegetation and subsequently colonize trees whose ground cover is comprised of preferred wild hosts (McClure, 1982).

On the other hand, the proximity of forest edges, hedgerows and patches of wild vegetation can influence the colonization, abundance and diversity of predators and parasites within a given agroecosystem, particularly when such ecotones provide hibernation and/or alternate feeding sites to natural enemies (van Emden, 1965). Studies conducted in soya bean fields revealed higher numbers of species and individuals of natural enemies in soya bean rows adjacent to natural vegetation than in rows in the center of the field (Mayse and Price, 1978; Altieri and Todd, 1981). In Czechoslovakia, apple orchards surrounded by deciduous forests tend to have a ten-fold higher abundance of the aphid predator, Coccinella quinquepunctata L., because the neighboring forest provides dormancy sites for the beetles where they hibernate in the forest litter (Lovei, 1981). In sparsely forested European countries, Pollard (1968) argues that much of the carabid fauna in crops is of a woodland origin and that many species are now dependent to a large extent on hedges for their continued existence in agricultural habitats.

Despite the above studies, we still know little about the dynamics of arthropod populations at the interface of agricultural and natural plant communities. For specific crops, some basic practical questions need answers: (a) to what extent do agricultural arthropods depend on non-crop habitats, (b) do arthropods move from wild vegetation borders to nearby crop fields and if so what triggers these movements, (c) do these borders influence the species diversity and abundance of beneficial arthropods in adjacent crop fields and (d) will these colonizing arthropods remain within adjacent crops regardless of the degree of vegetational diversity and management intensity of these fields?

In northern California, many apple orchards are distributed within a matrix of natural vegetation which provides abundant opportunities for the study of arthropod colonization and interhabitat exchanges of arthropods. Studies were conducted comparing the arthropod fauna of four dry-farmed apple orchards: (a) an "abandoned" orchard unmanaged and undisturbed for 25 years, (b) two "organic" orchards (not sprayed with synthetic pesticides), one clean cultivated and the other with a mixed grass (Bromus sp. and Hordeum sp.)-bell bean (Vicia faba L.) cover crop and (c) a "commercially" managed orchard (clean cultivated and subjected to chemical fertilizer and pesticide treatments). Although these orchards may be considered ecologically different, they shared similar boundaries of natural vegetation, allowing us to examine some of the questions posed above. 


\section{MATERIALS AND METHODS}

\section{Study sites}

The studies were conducted from April to September 1982 and 1983 in Sebastopol, California, $65 \mathrm{~km}$ north of San Francisco, a typical applegrowing region. The climate of the region is Mediterranean with mild, wet winters and hot, dry summers.

The organic and sprayed orchard sites were adjacent, whereas the abandoned orchard was located $2 \mathrm{~km}$ away. All were planted with "Rome Beauty" apples and had at least one bordering edge with communities of wild vegetation. The tree strata of these borders were dominated by coast live oak (Quercus agrifolia Nee), bay (Umbellularia californica Nutt), Douglas fir (Pseudotsuga menziesii (Mirb.) and Rhus sp., with a subordinated shrub layer dominated by Rubus spp. and Baccharis pilularis DC., with a diversified herb layer. Distance between the first apple row and the wild vegetation edge varied between 8 and $12 \mathrm{~m}$. Secondary succession in the abandoned orchard was well advanced, thus apple trees grew intermingled with Douglas fir, madrone (Arbutus menziesii Pursh), Baccharis and Rubus. The understory vegetation was dominated by weeds such as Whipplea modesta Torr., Castanea spp., Lonicera hispidula var. Californica jepson, Plantago lanceolata L. and various grasses. Detailed descriptions of the planting patterns, tree heights and cultural management practices for the orchards can be found in Altieri and Schmidt (1984).

\section{Sampling methods}

To maximize catches of flying and wind-carried arthropods at the orchard-woodland interface, two Malaise traps (Southwood, 1978) were placed in each orchard across "flight paths" between the first apple row and the adjacent woodland edge. Samples were taken May through September. Each Malaise trap contained a $1-l$ glass jar filled with alcohol (95\%), which was replaced every week and taken into the laboratory where trapped arthropods were counted and sorted into families and trophic guilds. Malaise trap data relating to the organic disked and cover-cropped orchards were combined, since both orchards were immediately adjacent, sharing the same edge vegetation.

Adult Hemiptera, Coleoptera, Diptera and Hymenoptera associated with the shrub and herb layer of the bordering woodland vegetation were sampled weekly with a $\mathrm{D}-\mathrm{Vac}^{\circledR}$ insect suction machine moved vertically from the foliage to the ground surface, across three randomly chosen $2-m$ vegetation transects. Five apple trees located in both the center and border of each orchard were randomly selected and the lower canopy of each tree was sampled weekly for $1 \mathrm{~min}$ with a D-Vac ${ }^{\circledR}$ to monitor populations of mobile, immature and adult arthropods. Species collected with the D-Vac ${ }^{\circledR}$ were 
compared with those collected in the Malaise traps to assess the similarity between species of the woodland-orchard interface to those at the center of the orchards.

Rosy apple aphid (Dysaphis plantaginea Passerini) infestation levels were assessed weekly by determining the proportion of infested twigs per tree from a random sample of 20 twigs per tree (a total of five center and five border apple trees per orchard). Adult and nymphal leafhopper densities were estimated by directly counting the number of individuals present on 10 random leaves on each of 20 twigs per tree. The impact of predaceous arthropods found on the foliage of woodland oaks and orchard trees was estimated on four occasions each year by hanging $258.5 \times 11.0-\mathrm{cm}$ paper cards from the branches of each of five oak trees in the bordering woodland and five apple trees in the center and border of each orchard. Each card contained approximately 50 glued eggs of Mediterranean flour moth (Anagasta kuehniella Zeller). Predation pressure was measured by determining numbers of eggs removed in an 18-h period.

Populations of ants, ground beetles and spiders were monitored by ran-domly placing five pitfall traps in the orchard center, five in the border row of apple trees immediately adjacent to the wild vegetation and five immediately within the edge of woodland surrounding each orchard. The pitfalls were filled with a mixture of $250 \mathrm{ml}$ water and $100 \mathrm{ml}$ antifreeze and allowed to remain in the field for a week, after which time they were replaced with new traps. Traps were taken into the laboratory where arthropods were identified, sorted and counted. This procedure was followed on 19 occasions from April to September each year. In addition to providing relative estimates of arthropod densities per unit area, pitfall catches reflected locomotory activity of cursorial species (Baars, 1979; Altieri and Schmidt, 1984).

Predation pressure of soil-inhabiting predators was determined on three occasions (early, mid and late summer) by placing $40 \quad 0.22-\mathrm{m}^{2}$ cardboard sheets in each orchard (20 in the center and 20 in the woodland edge) with 20 glued 4th instar potato tuberworm larvae (Phthorimaea operculella Zeller) per sheet. Predation pressure was determined as the number of larvae removed in an 18-h period.

Since each orchard comprised a single non-replicated experimental unit, inferential statistics were not applied to compare "between-orchard data" (Hurlbert, 1984). However, by treating each sampling unit (tree, pitfall, larval sheets and egg cards) as a replicate, "within-orchard" statistical differences in pitfall catches and predation were estimated using a Friedman 2 -way analysis of variance (Samways, 1981). 


\section{RESULTS AND DISCUSSION}

\section{Interception of arthropods with Malaise traps}

Figure 1 shows the total numbers of the dominant arthropods caught at the interface of the orchards and the wild vegetation borders. Low numbers of arthropods were collected in traps placed between the abandoned orchard and adjacent woodland. However, higher catches of parasitic $\mathrm{Hy}$ menoptera and predatory Neuroptera and Coleoptera were obtained at the interface of the disked organic orchard than either the sprayed or abandoned orchards. This result is also shown by the seasonal trends in the numbers of Coccinellidae (Coleoptera) intercepted by the Malaise traps (Fig. 2). Of the predatory groups, only Diptera (mainly Syrphidae) were intercepted in greater numbers at the sprayed orchard than at the disked organic orchard-woodland interface. Substantially more phytophagous Hemiptera (aphids and leafhoppers) were caught at the sprayed orchard than at the disked organic and abandoned orchard-woodland interface (Fig. 1). As observed in Fig. 3, early season catches of immature and winged rosy apple aphids were considerably higher at the interface of the sprayed orchard than at the interface of the organic and abandoned orchards.

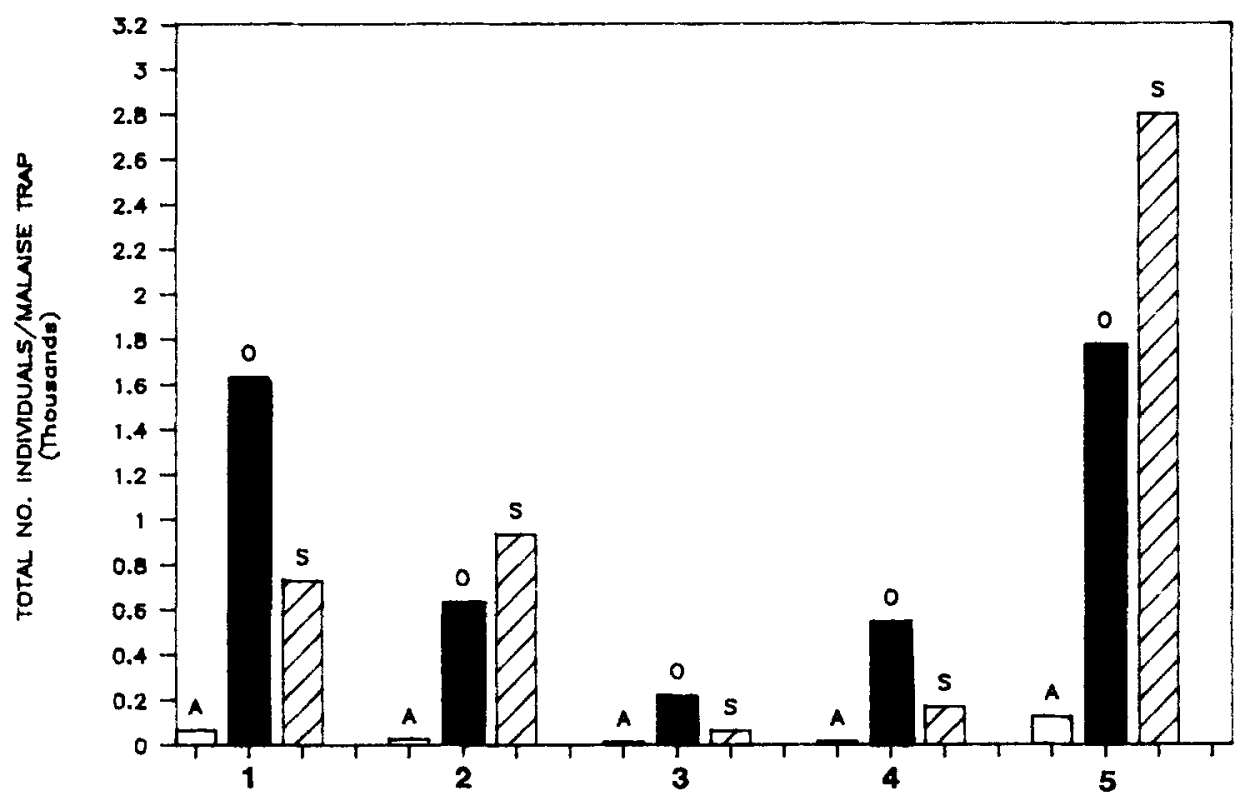

Fig. 1. Total number of arthropods (predators, larger parasitic Hymenoptera and phytophagous Hemiptera) caught in Malaise traps placed at the interface of abandoned (A), disked organic $(O)$ and sprayed $(S)$ orchards and adjacent woodlands from May through September 1982 in northern California $(1=$ Hymenoptera, mainly large Braconidae and Ichneumonidae, 2 = Diptera, mainly Syrphidae and Pipunculidae, $3=$ Neuroptra, mainly Raphidiidae, Chrysopidae and Hemrobiidae, 4 = Coleoptera, mainly Coccinellidae and Cantharidae and $5=$ phytophagous Hemiptera, mainly Aphididae and Cicadelidae). 


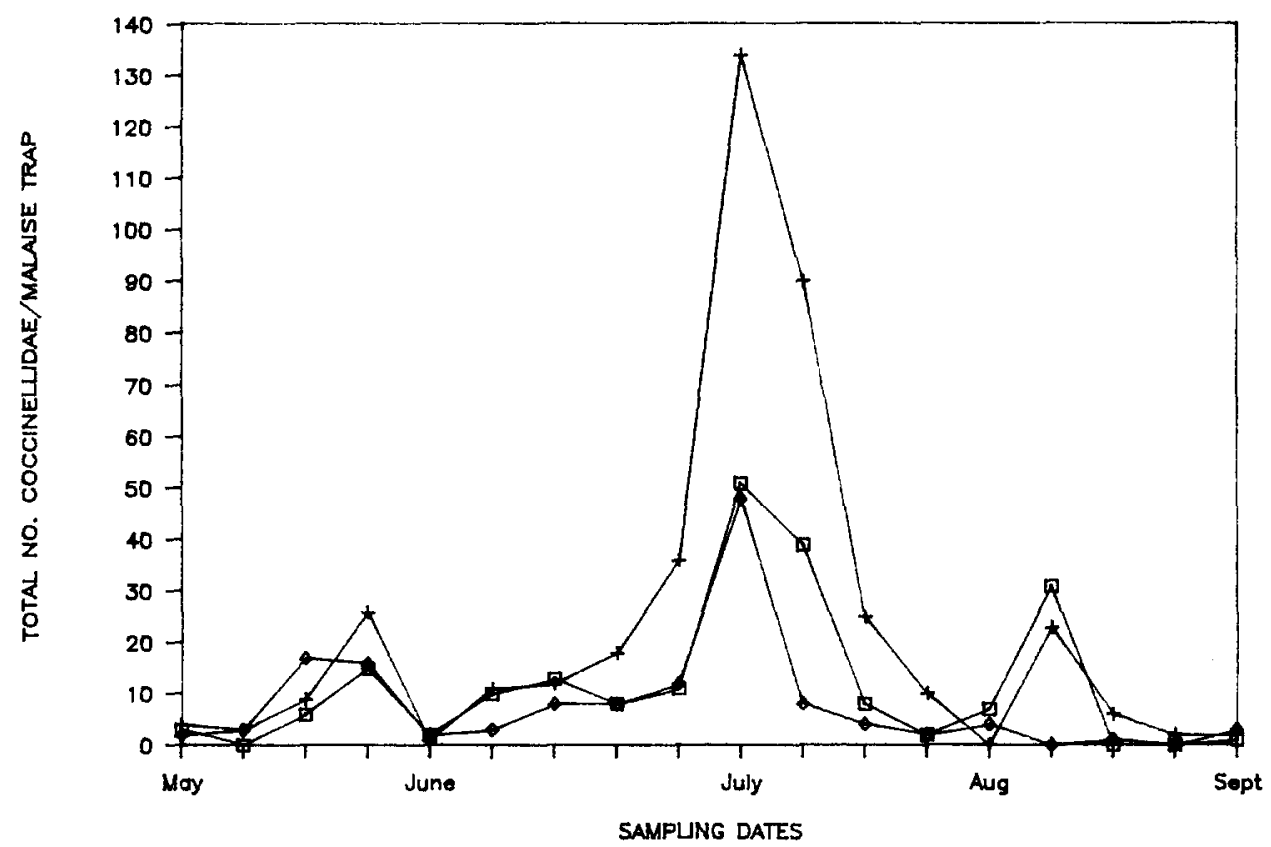

Fig. 2. Total number of Coccinellidae (Coleoptera) caught in Malaise traps placed at the interface of abandoned $(\square)$, disked organic $(+)$ and sprayed $(\diamond)$ apple orchards and adjacent woodlands.

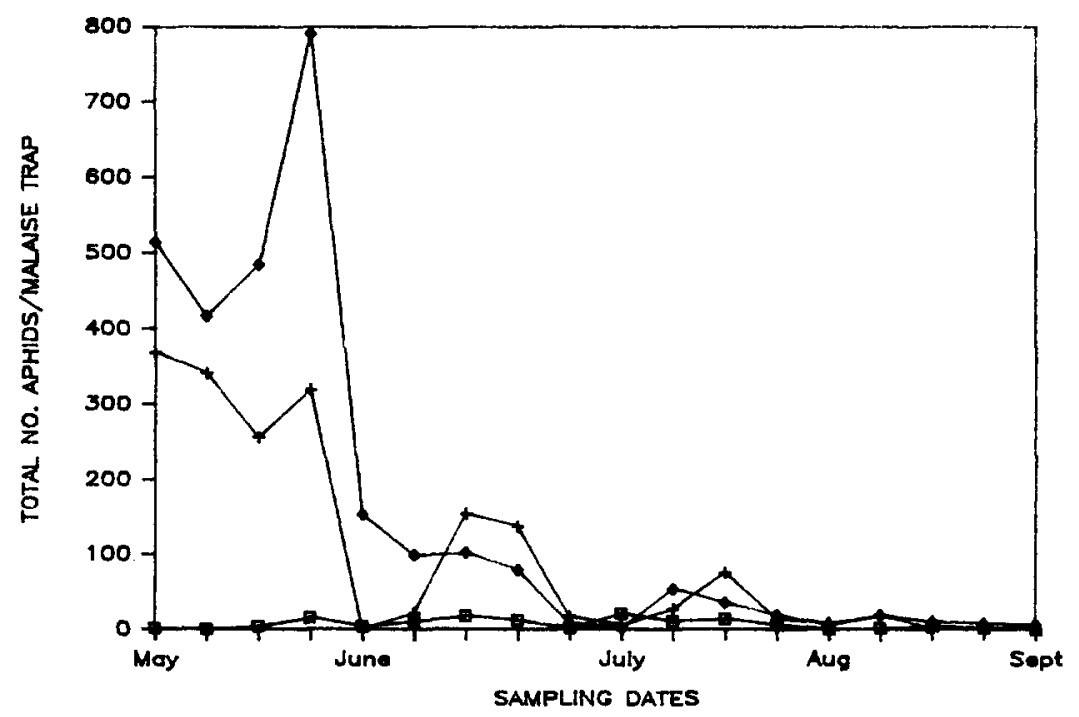

Fig. 3. Total number of rosy apple aphids (Dysaphis plantaginea) caught in Malaise traps placed at the interface of abandoned $(\square)$, disked organic $(+)$ and sprayed $(\diamond)$ apple orchards and adjacent woodlands. 
Arthropods sampled from foliage

\section{Phy tophagous species}

Rosy apple aphid and leafhopper densities increased with intensity of orchard management and vegetation simplification. Leafhopper populations reached higher densities on apple trees in the centers of both insecticidetreated and disked organic orchards than on trees in the vegetationally diverse (cover-cropped and abandoned) orchards (Fig. 4). Abandoned orchards were particularly characterized by low and stable leafhopper populations throughout the season. Rosy apple aphids were present until early July, reaching highest infestation levels during May and June in the disked organic orchard, followed by the cover-cropped and sprayed orchards. Rosy apple aphid colonies developed poorly in the abandoned orchard throughout the season. As with the leafhopper populations, apple trees located in the center of the organic orchards exhibited higher aphid infestations than trees located adjacent to the woodlands. These infestation differences between center and border apple trees were not significant in the abandoned and sprayed orchards (Table I).

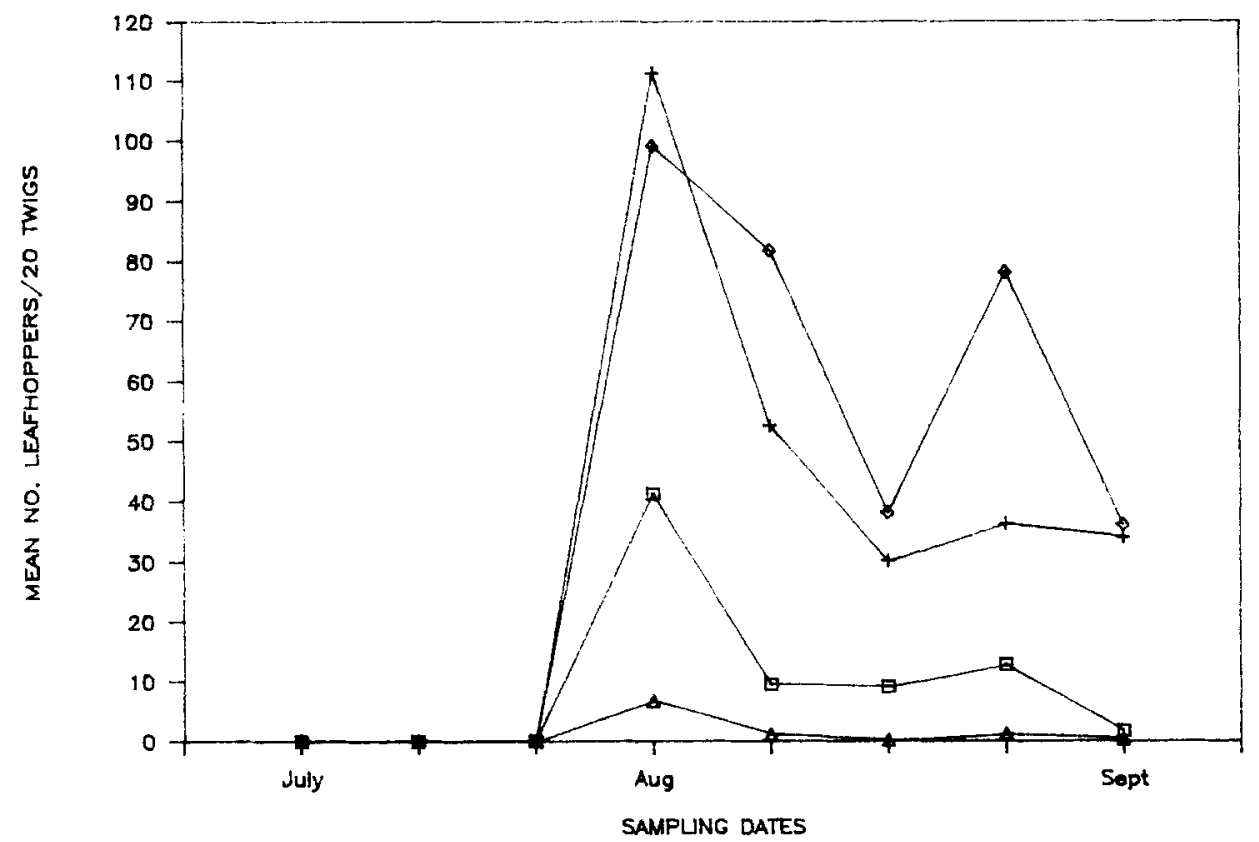

Fig. 4. Mean densities of leafhoppers on apple trees located within abandoned $(\Delta)$, organic with cover crop $(\square)$, disked organic $(+)$ and sprayed $(0)$ orchards in northern California. 


\section{TABLE I}

The effect of adjacent woodlands on the infestation levels of rosy apple aphis (Dysaphis plantaginea) in a range of apple orchards in northern California

\begin{tabular}{llr}
\hline Orchard system $^{1}$ & \multicolumn{2}{l}{ Aphid-infested twigs (\%) } \\
\cline { 2 - 3 } & $\begin{array}{l}\text { Apple trees adjacent to } \\
\text { woodland }\end{array}$ & $\begin{array}{l}\text { Apple trees in the center of the } \\
\text { orchards }\end{array}$ \\
\hline Abandoned & $4.2 \pm 0.7$ & $5.5 \pm 2.3$ \\
Organic, covercropped & $6.8 \pm 2.1$ & $17.1 \pm 6.7$ \\
Organic, disked & $9.8 \pm 3.2$ & $19.4 \pm 5.9$ \\
Sprayed & $20.2 \pm 5.6$ & $26.9 \pm 8.9$ \\
\end{tabular}

\footnotetext{
${ }^{1}$ Seasonal means \pm S.E. derived from five sampling dates in May-June 1982. Twenty twigs per apple tree (five center and five edge trees per orchard) were sampled on each occasion.
}

\section{Predatory species}

Insect predator abundance paralleled the plant complexity in each orchard. Predators were least abundant in the sprayed orchard and most numerous in the abandoned orchard. In general, predators reached higher densities on apple trees adjacent to the woodlands than in the orchard centers, however, these differences were only statistically significant in the disked organic orchard. Spiders showed a similar, but less marked trend. No differences in abundance were revealed for parasitic Hymenoptera, either between organic and abandoned orchards or border and center rows. Lowest densities, however, were observed in the sprayed orchard (Table II).

\section{TABLE II}

Seasonal abundances of arthropods on apple trees located in the borders and centers of a range of orchards in northern California

\begin{tabular}{|c|c|c|c|c|c|c|}
\hline \multirow[t]{3}{*}{ Orchard system ${ }^{1}$} & \multicolumn{2}{|c|}{ Predaceous insects $^{2}$} & \multicolumn{4}{|c|}{ Parasitic insects } \\
\hline & \multirow[b]{2}{*}{ Border } & \multirow[b]{2}{*}{ Center } & \multicolumn{2}{|c|}{ Hymenoptera } & \multicolumn{2}{|l|}{ Spiders } \\
\hline & & & Border & Center & Border & Center \\
\hline Abandoned & $9.1 \pm 2.7$ & $7.6 \pm 3.1$ & $1.2 \pm 0.4$ & $1.4 \pm 0.7$ & $3.7 \pm 1.0$ & $2.9 \pm 0.6$ \\
\hline $\begin{array}{l}\text { Organic, cover-cropped } \\
\text { Organic, disked } \\
\text { Sprayed }\end{array}$ & $\begin{array}{l}6.9 \pm 1.6 \\
9.5 \pm 3.4 \\
2.3 \pm 1.3\end{array}$ & $\begin{array}{l}4.6 \pm 1.8 \\
4.2 \pm 2.3 \\
1.5 \pm 0.6\end{array}$ & $\begin{array}{l}2.1 \pm 1.1 \\
3.8 \pm 1.6 \\
0.9 \pm 0.2\end{array}$ & $\begin{array}{l}1.4 \pm 0.8 \\
1.6 \pm 1.1 \\
0.6 \pm 0.3\end{array}$ & $\begin{array}{l}2.9 \pm 1.4 \\
4.9 \pm 2.1 \\
1.0 \pm 0.6\end{array}$ & $\begin{array}{l}1.3 \pm 0.9 \\
1.6 \pm 1.3 \\
0.4 \pm 0.3\end{array}$ \\
\hline
\end{tabular}

\footnotetext{
${ }^{1}$ Seasonal means \pm S.E. derived from 18 sampling dates in 1982. Five trees in the border and center of each orchard were sampled with a $\mathrm{D}-\mathrm{Vac}^{\circledR}$ on each occasion.

${ }^{2}$ Adult Coccinellidae, Cantharidae (Coleoptera), Chrysopidae, Hemerobiidae (Neuroptera) and predaceous Hemiptera.
} 
$\mathrm{D}-\mathrm{Vac}{ }^{\circledR}$ samples taken from the shrub and herb layer of the woodland edges, revealed that throughout May and June, edges of the organic orchards supported considerably more natural enemies than the edges of the sprayed or abandoned orchards. These trends are well illustrated in Fig. 5 for Coccinellidae and are typical for other groups of predators such as Hemerobiidae (Neuroptera), Cantharidae (Coleoptera) and spiders. Interestingly $\mathrm{D}-\mathrm{Vac}^{\circledR}$ samples taken on the edge of the disked organic orchard revealed a population peak for Coccinellidae in mid-June, whereas Malaise trap data revealed a catch peak in mid-July.

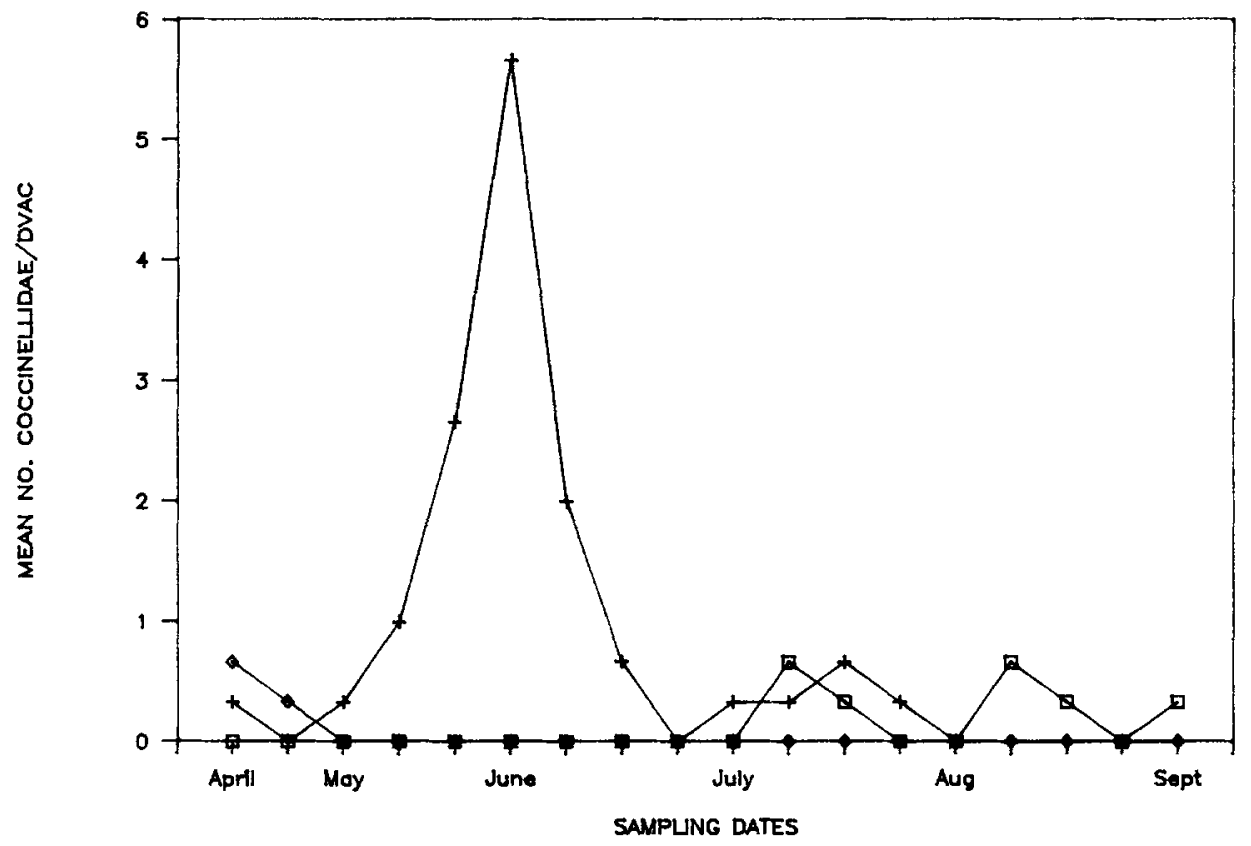

Fig. 5. Mean number of Coccinellidae (Coleoptera) associated with the herb-shrub layer of woodlands adjacent to abandoned $(\square)$, disked organic $(+)$ and sprayed $(\diamond)$ apple orchards in northern California.

\section{Pitfall trapping of ground-dwelling predators}

The total numbers of ants, spiders and carabid beetles caught in pitfall traps throughout the season in the various orchards are presented in Table III. Ant species collected in the edges of the managed orchards were also collected in the borders and centers of these orchards, suggesting that a proportion of the ant communities living in the surrounding habitats colonized the planted orchards. The total number of ants caught in the pitfalls was consistently higher at the edges of the organic and sprayed orchards (managed orchards) than at the orchards' borders or centers. A declining 


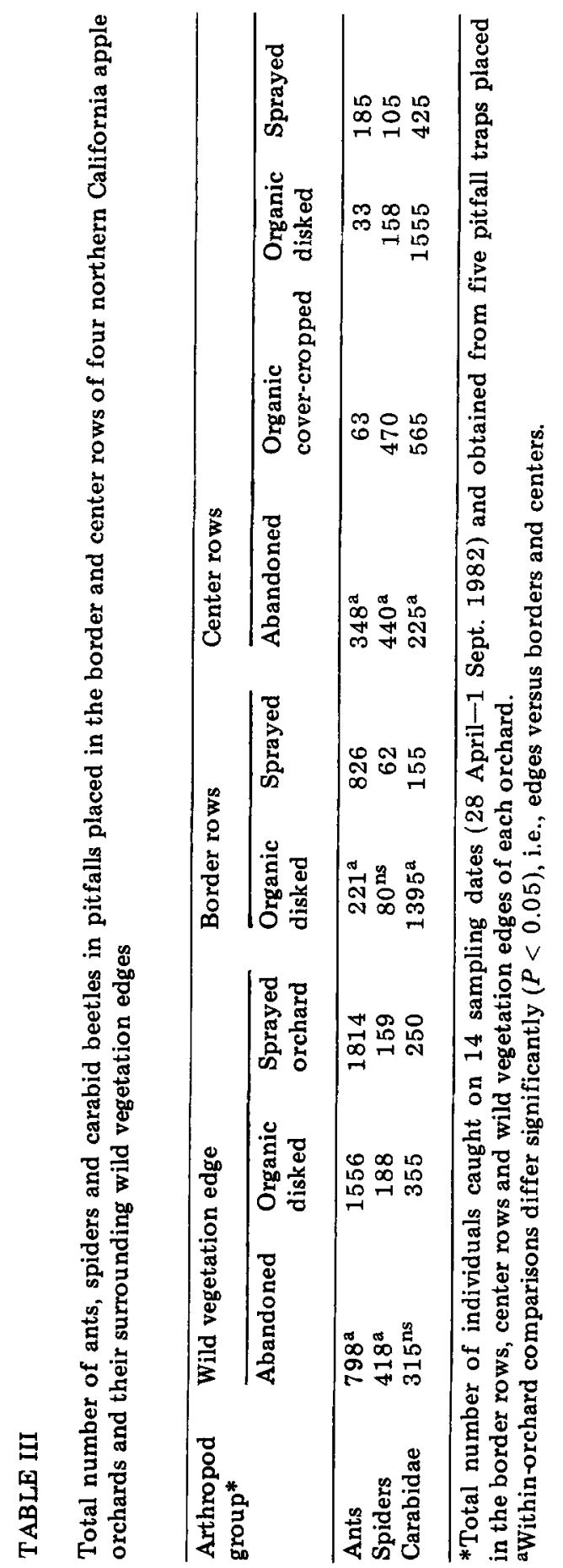


gradient in abundance occurred from the edge to the center of the orchards. This gradient, however, was not as marked in the abandoned orchard, where ant species composition and overall patterns of ant abundance were more or less uniform from edge to center after mid-May. These trends could be explained on the basis of the structural similarities of the centers and edges, unlike the situation in the centers of the clean cultivated systems which lacked the diversity of grasses and herbs characteristic of the edges.

Overall, higher ant catches were obtained in the wild vegetation edges of the managed rather than the abandoned orchards. Total pitfall ant catches in the apple border row were higher in the sprayed than in the clean cultivated organic orchard. Ant catches in the centers of the orchards were higher in the abandoned and sprayed orchards than in the organic ones and more ants were caught in the cover-cropped orchard than in the disked one. A detailed description of ant population trends in these orchards is given in Altieri and Schmidt (1984).

Spider catches were substantially higher in the wild vegetation edges than in the border rows of the organic and sprayed orchards, however, spider catches in the centers reached similar or higher values than those obtained in the edges. Substantially more spiders were caught in the centers of the abandoned and cover-cropped orchards than in the centers of the sprayed and disked organic orchards. Total catches of Carabidae were

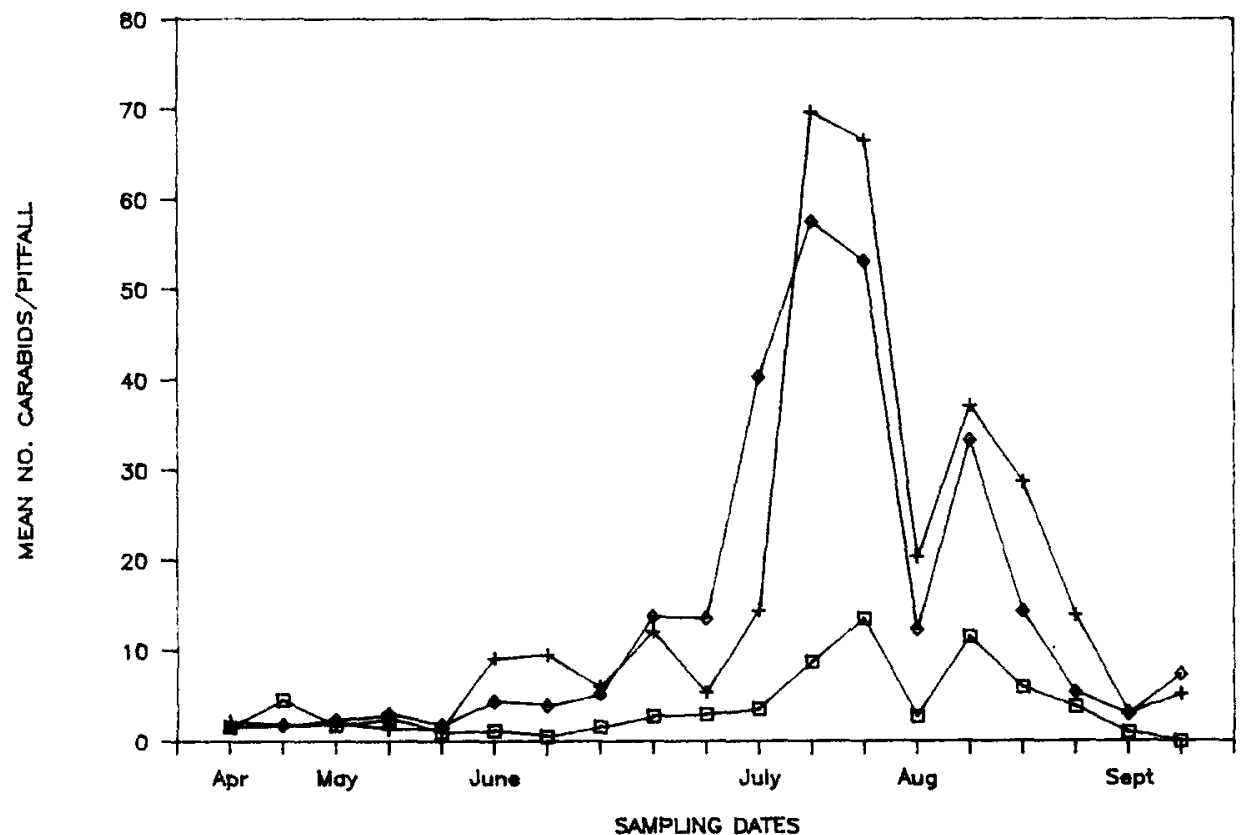

Fig. 6. Mean catches of Carabidae in pitfalls placed in the bordering woodland $(\square)$, adjacent apple row $(\diamond)$ and center apple row $(+)$ in a disked organic orchard in Sebastopol, California. 
higher in the center of the sprayed and disked organic orchards than in the edges. Conversely, catches in the edge of the abandoned orchard were slightly higher than in the center. An increasing gradient in carabid catches developed throughout the season from edge to center in the disked organic orchard (Fig. 6).

\section{Predation pressure}

In both years, removal rates of potato tuberworm (Phthorimaea operculella) larvae from cardboard sheets were consistently higher in the center of the abandoned orchard, followed by the organic orchards, whereas low predation was observed in the center of the sprayed orchard (Table IV).

\section{TABLE IV}

Removal of Mediterranean flour moth eggs, Anagasta kuehniella (placed on the trees) and of potato tuberworm larvae, Phthorimaea operculella (placed on the ground) by predators in the center and border rows and surrounding edges of various orchards in Sebastopol, California

\begin{tabular}{|c|c|c|c|c|}
\hline \multirow[t]{2}{*}{$\overline{\text { Orchard system }}$} & \multicolumn{2}{|c|}{ Eggs removed $^{1}(\%)$} & \multicolumn{2}{|c|}{ Larvae removed $^{2}(\%)$} \\
\hline & 1982 & 1983 & 1982 & 1983 \\
\hline \multicolumn{5}{|l|}{ Abandoned } \\
\hline Center & $38.0 \pm 9.2^{\mathrm{ns}}$ & $53.1 \pm 16.7$ & $86.9 \pm 14.5^{\mathrm{ns}}$ & $63.1 \pm 23.3$ \\
\hline Border & $42.0 \pm 10.7$ & - & - & - \\
\hline Edge & $36.0 \pm 4.2$ & - & $84.6 \pm 15.2$ & - \\
\hline \multicolumn{5}{|c|}{ Organic, cover-cropped } \\
\hline Center & $36.9 \pm 11.7$ & $33.1 \pm 5.1$ & $72.8 \pm 9.3$ & $66.8 \pm 26.0$ \\
\hline \multicolumn{5}{|l|}{ Organic, disked } \\
\hline Center & $25.0 \pm 6.2^{\mathrm{a}}$ & $23.7 \pm 7.3$ & $61.5 \pm 8.2^{\mathrm{ns}}$ & $41.9 \pm 12.3$ \\
\hline Border & $34.1 \pm 9.1$ & - & - & - \\
\hline Edge $^{3}$ & $43.1 \pm 7.3$ & - & $70.5 \pm 10.6$ & - \\
\hline \multicolumn{5}{|l|}{ Sprayed } \\
\hline Center & $21.0 \pm 3.2^{\mathrm{a}}$ & $23.2 \pm 6.8$ & $17.0 \pm 6.2^{\mathrm{a}}$ & $25.0 \pm 9.6$ \\
\hline Border & $26.0 \pm 8.0$ & - & - & - \\
\hline Edge & $33.0 \pm 7.2$ & - & $32.7 \pm 7.6$ & - \\
\hline
\end{tabular}

\footnotetext{
${ }^{1}$ Predation pressure on the eggs was estimated on four occasions by hanging $258.5 \times$ $11.0-\mathrm{cm}$ paper cards (with 50 moth eggs each) for $18 \mathrm{~h}$ from the branches of each of five trees in the center, border and edge of each orchard.

${ }^{2}$ Means \pm S.E. of three sampling dates. Larval removal data were obtained by placing on the ground $4022 \times 22-\mathrm{cm}$ cardboard sheets (20 in the center and 20 in the edge) each containing 20 glued 4 th instar larvae. Predation pressure was measured by determining removal of larvae in an 18 -h period.

${ }^{3}$ Data applies to both disked organic and cover-cropped orchards, as both orchards were immediately adjacent, sharing the same edge vegetation.

aWithin orchard comparisons differ significantly $(P<0.05)$.
} 
Predation was greater in the center of the organic orchard with cover than in the center of the disked organic orchard. On average, larval removal was significantly higher in the edges of the disked organic and sprayed orchards than in the centers of these same orchards. Presumably, cultivation and insecticide applications disrupted ground arthropod communities in the centers of the disked organic and sprayed orchards, consequently confining foraging to the edges. Removal rates, however, remained similar in the wild vegetation edges and centers of the organic cover and abandoned orchards.

In 1982, predation of Anagasta kuehniella eggs placed on the trees was consistently higher in the edges than in the center tree rows of the managed orchards (Table IV). Again, no differences in predation were observed between edge and center in the cover-cropped and abandoned systems. In both years, a clear gradient in predation pressure was observed in the centers of the orchards, declining from abandoned to sprayed.

\section{CONCLUSIONS}

Our data indicate that in Sebastopol, California, there is considerable exchange of arthropods at the interface of wild vegetation edges and adjacent apple orchards. This is illustrated by the considerable number of arthropods intercepted by the Malaise traps placed at the interface of woodland and managed orchards. Little exchange seemed to take place between the abandoned orchard and surrounding woodlands, which shared similar patterns of vegetational and structural diversity. Apparantly, the greater the structural differences between orchards and adjacent habitats, the more dramatic the degree of exchange of arthropods at the interface.

Although our data more properly express the number of arthropod intecepted across woodland-orchard "paths", it is reasonable to assume that most arthropods invaded the orchards from the wild edges (McClure, 1982). In general, more natural enemies and less herbivores (rosy apple aphids and leafhoppers) invaded the two organic orchards than invaded the sprayed one. After this initial invasion, arthropod distribution within the orchards was affected by the intensity of orchard management, the plant successional features of each orchard and the proximity of the apple trees to the edges. A declining gradient in predator abundance was observed with decreased vegetational diversity and increased intensity of management. Herbivores exhibited the opposite trend. Greater numbers of predaceous arthropods become established in the organic orchards than in the sprayed orchard and predator densities on trees immediately adjacent to the wild edges were higher than on trees in the center of the orchards. Higher densities of aphids and leafhoppers were observed on trees in the sprayed orchard than in all other orchards. In addition, colonies of rosy apple aphids selectively developed more on trees in the center of the orchard than on trees growing in proximity to the woodlands. 
Although arthropod exchange was low between the abandoned orchard and its woodland border, this system exhibited the greatest abundance of predators and lowest density of herbivores per tree throughout the season. Advanced succession resulted in increased natural enemy abundance, possibly a consequence of increased diversity of resources and alternate food. Herbivore densities were reduced, but it is not clear whether this was due to the increased abundance of natural enemies or to changes in tree growth (foliar levels of nutrients, new tissue growth, etc.) which in turn may have affected herbivore reproduction. Site differences could also have affected these trends, since the abandoned orchard was located $2 \mathrm{~km}$ from the other orchards.

Considerable exchange of cursorial arthropods occurred between managed orchards and surrounding woodland. Ants concentrated more along the wild edges than in the centers of the orchards. Conversely, spiders and carabids were more abundant in the centers than in the edges. However, larval removal was substantially higher in the edges of the organic and sprayed orchards than in the centers. Presumably, cultivation and insecticide applications disrupted ground arthropod populations in the orchard centers, confining foraging to the edges (Altieri and Schmidt, 1984).

In summary, several arthropod species collected in the woodland edges were intercepted at the orchard interfaces and later collected within the orchards, suggesting that the development of apple orchard arthropod communities can be influenced by surrounding natural vegetaion. Studies of these relationships may lead to new pest management practices based on various frequencies of ground cover alteration, manipulation of border vegetation composition and permanence and other techniques that affect orchard diversity, proximity of trees to edges and consequently tree growth and vigor. Realistically, the ecological setting of an orchard (surrounding environment) is a more difficult factor to manage since its dimensions extend beyond the farm boundary. Plant succession and degree of management and inputs are more amenable to management (Croft and Hoyt, 1983).

More research is clearly warranted to determine further the influence of adjacent habitats and the within-orchard degree of vegetational diversity on the dynamics of colonizing arthropods in a range of agricultural systems.

\section{REFERENCES}

Altieri, M.A. and Schmidt, L.L., 1984. Abundance patterns and foraging activity of ant communities in abandoned, organic and commercial apple orchards. Agric. Ecosystems Environ., 11: 341-352.

Altieri, M.A. and Todd, J.W., 1981. Some influence of vegetational diversity on insect communities of Georgia soybean fields. Prot. Ecol, 3: 333-338.

Baars, M.A., 1979. Catches in pitfall traps in relation to mean densities of carabid beetles. Oecologia, 41: 25-46. 
Croft, B.A. and Hoyt, S.C., 1983. Integrated Management of Insect Pests of Pome and Stone Fruits. Wiley, New York, $454 \mathrm{pp}$.

Dambach, C.A., 1948. Ecology of Crop Field Borders. Ohio State University Press, Columbus, $\mathrm{OH}, 140 \mathrm{pp}$.

Hurlbert, S.H., 1984. Pseudoreplication and the design of ecological field experiments. Ecol. Monogr, 54: 187-211.

Lovei, G.C., 1981. Coccinellid community in an apple orcchard bordering a deciduous forest. Acta Phytopathol. Acad. Sci. Hung., 16: 143-150.

Mayse, M.A. and Price, P.W., 1978. Seasonal development of soybean arthropod communities in east central Illinois. Agro-ecosystems, $4: 387-405$.

McClure, M., 1982. Factors affecting colonization of an orchard by leafhopper (Hom. optera:Cicadellidae) vectors of peach x-disease. Environ. Entomol., 11: 695-699.

Pollard, E., 1968. Hedges IV. A comparison between the carabidae of a hedge and field site and those of a woodland glade. J. Appl. Ecol., 5: 649-657.

Samways, M.J., 1981. Comparison of ant community structure in citrus orchards under chemical and biological control of red scale, Aonidiella aurantii (Maskell) (Hemiptera: Diaspididae). Bull. Entomol. Res., 71: 663-670.

Southwood, T.R.E., 1978. Ecological Methods. 2nd edn. Chapman and Hall, London, $524 \mathrm{pp}$.

Van Emden, H.F., 1965. The role of uncultivated land in the biology of crop pests and beneficial insects. Sci. Hortic., 17: 121-136.

Wainhouse, D. and Coaker, T.H., 1981. The distribution of carrot fly (Psila rosae) in relation to the fauna of field boundaries. In: J.M. Thresh (Editor), Pests, Pathogens and Vegetation: The Role of Weeds and Wild Plants in the Ecology of Crop Pests and Diseases. Pitman, Massachusetts, pp. 263-272. 